\title{
NONLINEAR INTERACTION BETWEEN DIURNAL TIDAL AND 2-DAY WAVE IN THE METEOR WINDS OBSERVED AT CACHOEIRA PAULISTA-SP AND SÃO JOÃO DO CARIRI-PB, BRAZIL: A CASE STUDY
}

\author{
Edvaldo de Oliveira Alves ${ }^{1}$, Lourivaldo Mota Lima ${ }^{1}$, Amauri Fragoso de Medeiros², \\ Ricardo Arlen Buriti2 ${ }^{2}$, Paulo Prado Batista ${ }^{3}$ and Barclay Robert Clemesha ${ }^{3}$
}

\begin{abstract}
Simultaneous measurements of meteor winds obtained in São João do Cariri-PB and Cachoeira Paulista-SP, Brazil, during June-July 2008 were used to investigate the occurrence of nonlinear coupling between atmospheric wave modes. The wind spectrum showed the quasi simultaneous presence of spectral energy peaks in the periods near 16, 24 and 48 hours, consistent with the occurrence of interaction between 48-h and 24-h waves, and the generation of 16-h waves. From the bispectral analysis, it was possible to confirm the occurrence of a 16-hour secondary wave generated by non-linear coupling between the 2-day and diurnal tide primary waves.
\end{abstract}

Keywords: atmospheric tide, bispectral analysis, meteor radar.

RESUMO. Medidas simultâneas de ventos meteóricos obtidos em São João do Cariri-PB e Cachoeira Paulista-SP, Brasil, durante os meses de junho e julho de 2008 , foram usadas para investigar a ocorrência de acoplamento não linear entre modos de ondas atmostéricas. Os espectros dos ventos evidenciaram a presença quase simultânea de picos de energia espectral nos períodos de 16, 24 e 48 horas, compatíveis com a ocorrência de interação entre as ondas de 48 e 24 horas, e a geração da onda de 16 horas. Através de análise biespectral foi possível confirmar que a onda secundária de 16 horas foi gerada pelo acoplamento não linear entre as ondas primárias de 2 dias e a maré diurna.

Palavras-chave: maré atmosférica, análise biespectral, radar meteórico.

\footnotetext{
1 Universidade Estadual da Paraíba, Centro de Ciências Tecnologia, Departamento de Física, Rua Juvêncio Arruda, s/n, Bodocongó, 58109-790 Campina Grande, PB, Brazil. Phone: +55(83) 3315-3371 - E-mails: eoalves@uepb.edu.br; Imlima@uepb.edu.br

2Universidade Federal de Campina Grande, Unidade Acadêmica de Física, Av. Aprígio Veloso, 882, Bloco CY, Bodocongó, 58109-970 Campina Grande, PB, Brazil. Phone: +55(83) 2101-1196 - E-mails: afragoso@df.ufcg.edu.br; rburiti@df.ufcg.edu.br

${ }^{3}$ Instituto Nacional de Pesquisas Espaciais, Av. dos Astronautas, 1758, 12245-970 São José dos Campos, SP, Brazil. Phone: +55(12) 3208-7143; Fax: +55(12) 3208-6740 - E-mails: ppbatista@laser.inpe.br; brc@laser.inpe.br
} 


\section{INTRODUCTION}

The daily heating by the sun results in a much more intense tidal effect in the atmosphere, as compared to that caused by the gravitational action. Migrant solar tides are induced mainly by radiation absorption in the near infrared by water vapor in the troposphere; in the ultraviolet by the ozone in the stratosphere and lower mesosphere; in the Schumann-Runge bands and continuum by $\mathrm{O}_{2}$ and $\mathrm{N}_{2}$ in the lower thermosphere; and, in the extreme ultraviolet by the 0 in the high thermosphere (Beer, 1975; Forbes, 1982).

Theoretical studies show that the diurnal tide propagating modes are concentrated in low latitudes regions (Chapman \& Lindzen, 1970), and according to the mechanical models (Forbes \& Vial, 1989; Hagan et al., 2001) the migrant solar diurnal tide has maximum amplitudes in the winds near $20^{\circ}$ latitudes. Amplitude and phase of the tidal components observed in the MLT (Mesosphere and Lower Thermosphere) show small and large scale changes over time; for example, interannual, inter-seasonal and intra-seasonal or even weekly and daily variations.

Some studies suggest that the interannual variations observed in the component of the diurnal tide, in the MLT at low latitudes, are connected with the Quasi-Biennial Oscillation (QBO) of the winds in the equatorial stratosphere (Vincent et al., 1998). Studies using the Global-Scale Wave Model (GSWM) showed that the diurnal tide in the MLT region is affected by changes in zonal mean wind component (Hagan et al., 1999). Simulations with the Canadian Middle Atmosphere Model (CMAM) showed that the diurnal tide in the MLT is sensitive to changes in the zonal mean winds (McLandress, 2002).

Gurubaran et al. (2005) reported a correlation between variations of MLT tidal winds and El Niño-Southern Oscillation (ENSO), caused mainly by the migrant diurnal component resulting from solar absorption by water vapor, according to Lieberman et al. (2007).

The migrant diurnal tide component in the MLT also presents an important semiannual variation, in which the amplitudes reach maximum values during spring and autumn and minimum around the solstices. This behavior has been attributed to interhemispheric symmetry of the strong latitudinal gradients of average winds in the summer mesosphere, along with semi-annual variation of tropospheric warming (McLandress, 2002). Nonlinear interaction between the diurnal tide and planetary waves has also been suggested to explain the semiannual variation observed in the diurnal tide component (McLandress, 1997).

The variations in periods of planetary waves observed in the components of atmospheric tides have received special attention in recent years. Theoretical (Teitelbaum et al., 1989) and experimental (Pancheva, 2006; Teitelbaum \& Vial, 1991) studies hypothesize that this variation is due to the interaction between atmospheric tides and planetary waves, which can be explained by considering the non-linear terms of the motion equations.

On the other hand, a wave with period near 2-day is a prominent feature of the MLT region during the summer season. According to the theoretical studies, the $\sim 2$-day period wave was identified as a normal planetary wave that propagates in the east-west direction with wave number 3 (Salby, 1981). An alternative explanation, based on stability analysis, proposes that the $\sim 2$-day wave is caused by baroclinic instability areas over the summer stratospheric jet flowing from east to west (Plumb, 1983). The possibility that the $\sim 2$-day wave may be generated by a combination of the two mechanisms has been further explored by theoretical studies (Salby \& Callaghan, 2001). Another aspect that has been observed is that, in general, the fast growth of the 2-day wave during the summer season occurs simultaneously with a decrease in the diurnal tide amplitude (Walterscheid \& Vincent, 1996; Lima et al., 2004).

The presence of 16-hour period oscillations during amplification events of the $\sim 2$-day wave is sometimes attributed to the interaction between the $\sim 2$-day wave and the tide, which has been treated from the nonlinear viewpoint (Pancheva, 2006; Teitelbaum \& Vial, 1991).

This study analyzes the possible nonlinear resonant interaction between atmospheric diurnal tide with 2-day wave and the consequent generation of the 16-hour wave, from observations of MLT winds obtained from meteor radars in São João do Cariri-PB and Cachoeira Paulista-SP.

\section{RESONANT INTERACTION}

The resonant interaction is associated with the wave-wave interaction that satisfies certain resonant conditions. If the waves interact as a trio of resonant waves (resonant triplet) with frequencies $\omega_{1}, \omega_{2}$ and $\omega_{3}$ and their corresponding complex wave vectors $k_{1}, k_{2}$ and $k_{3}$, then the resonant conditions are (Beer, 1975);

$$
\begin{aligned}
& \omega_{1}+\omega_{2}+\omega_{3}=0, \\
& k_{1}+k_{2}+k_{3}=0 .
\end{aligned}
$$

Since $k$ and $\omega$ may be positive or negative, the third member of the trio resonant may assume two values:

$$
\begin{gathered}
\omega_{3}=\omega_{1} \pm \omega_{2}, \\
k_{3}=k_{1} \pm k_{2} .
\end{gathered}
$$


If two evanescent waves, whose wave number magnitudes are almost equal, interact, the frequency difference $\left(\omega_{1} \pm \omega_{2}\right)$ can be arbitrarily small while the difference between the wave numbers is comparable, in magnitude, with $k_{1}$ and $k_{2}$. Although $k_{1}$ and $k_{2}$ magnitudes are very close, this does not necessarily apply for their directions, then the resonance condition (4) can be represented by a closed triangle vector diagram as shown in Figure 1.

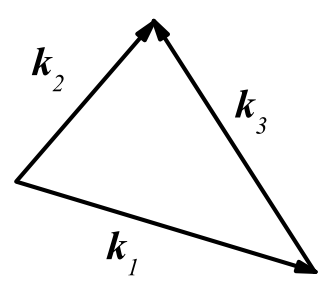

Figure 1 - Vector diagram of horizontal wavenumber for a resonant frequency triplet.

Varying the amplitude of $k_{2}$ to about $k_{1}$, it is possible to obtain an internal wave mode $\left(k_{3}, \omega_{3}\right)$. This mechanism may be a possible source for internal waves if the wave $\left(k_{3}, \omega_{3}\right)$ is able to extract energy from the evanescent waves to which it is attached (Beer, 1975).

Spizzichino (1969a, b), through investigations on nonlinear resonant interactions, pointed out that many gravity waves observed in meteoric heights arise from the interaction between the diurnal tide and gravity waves trapped below the mesopause. Another conclusion was that the prevailing wind produces an additional meridional circulation through the nonlinear interaction with the atmospheric oscillations; and that the tidal interaction between $S_{1}$ and $S_{2}$ produces a downwards propagating diurnal tide.

\section{OBSERVATIONS AND ANALYSIS}

This study was based on the observations of winds near the mesopause region. The wind data were estimated from measurements obtained in June and July 2008, by the meteor radars located at São João do Cariri-PB $\left(7.4^{\circ} \mathrm{S}, 36.5^{\circ} \mathrm{W}\right)$ and Cachoeira Paulista-SP $\left(22.7^{\circ} \mathrm{S}, 45^{\circ} \mathrm{W}\right)$, Brazil.

In the estimation of the wind, the trail of ionized gas formed when a meteoroid enters the atmosphere and undergoes ablation is used to reflect the energy transmitted by the radar. The meteoric trail is carried by the wind and the signal frequency reflected to the radar undergoes a Doppler shift. The Doppler shift, along with the delay of the reflected pulse and the arrival angle of the echo, allows determining the wind components.
The meteor radar systems VHF All-Sky Interferometric Meteor Radar (SKYMET) operate in the $35.24 \mathrm{MHz}$ frequency, with a repetition rate of 2144 pulses per second and $12 \mathrm{~kW}$ power peak. Each system illuminates a large region of the atmosphere through a three element Yagi-type transmitting antenna, and reflected echoes are detected by a set of five receiving antennas, whose asymmetrical cross distribution in the soil allows determining the angular location of the trail from the phase differences among the five antennas.

The echoes detected every hour and located on each of the 4-km-thick seven layers (centered at altitudes of 81, 84, 87, 90, 93, 96 and $99 \mathrm{~km}$ ) were used to estimate the winds.

The wavelet transform, a useful tool to analyze non-stationary series, was used to assess the temporal distribution of the frequency spectrum (Kumar \& Foufoula-Georgiou, 1997; Torrence \& Compo, 1998). The wavelet transform has also been used to investigate wavy perturbations observed in the winds of the near mesopause region (Pancheva, 2000; Lima et al., 2005). Amplitudes and phase structures of the oscillations were obtained by harmonic analysis.

To identify possible periodicities arising from the interaction of primary waves, the Lomb-Scargle periodogram (Scargle, 1982) was employed to obtain the localized spectra. The well-defined statistical behavior is an important feature of the Lomb-Scargle periodogram. To evaluate the confidence level of the spectrum peaks in the periodogram, the null hypothesis is considered, in which it is assumed that the data are independent random values, that is, pure Gaussian noise.

The bispectrum technique was also used to investigate a possible nonlinear coupling between the diurnal tide component and planetary wave modes. The bispectrum retains phase information and, through it, it is possible to identify nonlinear interaction processes that can generate phase couplings. The bispectral analysis is based on moment techniques, which are inserted through the cumulants and cumulant spectrum concepts, and can be used to analyze non-Gaussian signals aiming to, among other things, detect and characterize the non-linearity of signals (Nikias \& Petropulu, 1993).

The bispectrum is equivalent to the two-dimensional Fourier transform of the sequence of third order moments. It gives a measure of the multiplicative interactions of frequency components. The bispectrum represents the contribution of the average product of three Fourier components, where one frequency is equal to the sum (or difference) of the other two. The bispectrum is nonzero only when the resonance conditions are fully met (Pancheva, 2000). 


\section{RESULTS}

Figures 2 and 3 show the wind data for Cachoeira Paulista-SP and São João do Cariri-PB, in east-west (zonal) and north-south (meridional) directions, and their spectra obtained by the Morlet wavelet transform. The wind data are representative of the layer centered at $90 \mathrm{~km}$ altitude, during June and July 2008. Figure 2 shows that winds for both components and sites have distinct variations over time.
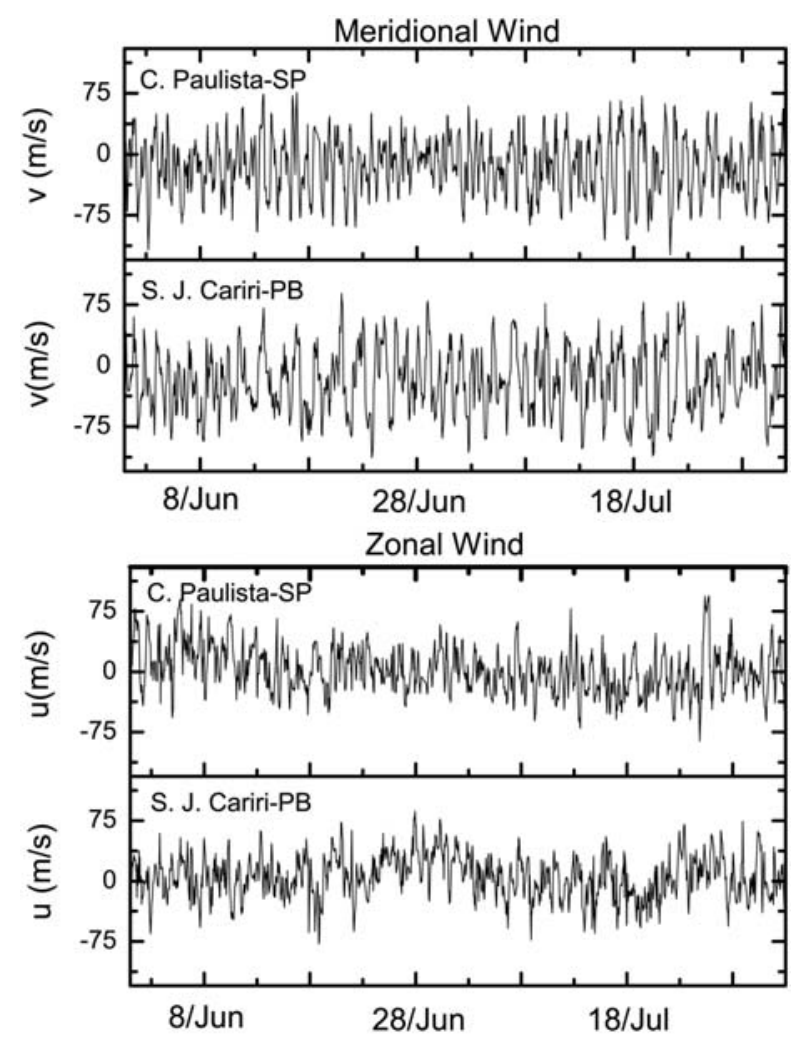

Figure 2 - Wind components in the east-west (zonal) and north-south (meridional) directions obtained during June and July from measurements by meteor radar at Cachoeira Paulista-SP and São João do Cariri-PB. The winds are representative of the $90 \mathrm{~km}$ altitude centered layer.

The events with almost simultaneous presence of spectral energy, for the periods between $\sim 12$ and 48 hours, suggest the occurrence of interaction between atmospheric waves. According to the theory, the interaction between the 24-hour (diurnal tide) and $\sim 48$-hour waves can generate waves with periods of $\sim 16$ and $\sim 48$ hours. To discriminate the periodicity present in the wind measurements during the events with the possibility of interaction between atmospheric wave modes, the LombScargle periodograms were obtained and the results can be seen in Figures 4 and 5, where the dashed line indicates 95\% confidence level. To evaluate the confidence level of the spectrum peaks in the periodogram, the null hypothesis is considered, where data are assumed as independent random values, that is, pure Gaussian noise according to Scargle (1982) and Hornes \& Baliunas (1986).

The results of the bispectral analysis for the intervals between 16 and 29 June to $87 \mathrm{~km}$ altitude, and between 15 and 28 July to $90 \mathrm{~km}$ altitude, are represented in Figures 6 and 7 , respectively. In the processing, 5 segments containing 6 days of data with 4 overlapping days were considered. The coherence between the interactions of the harmonic phases is characterized by the presence of maxima in the bispectrum. The peak indicates the phase coupling of the three frequencies involved, where the $x$ and $y$ coordinates indicate the two primary frequencies while the frequency resulting from coupling is represented by a diagonal across the peak, which intercepts the $x$ and $y$ axes in the same values.

\section{DISCUSSION}

The analysis of the wavelet spectra in Figure 3 shows that both wind components at two sites are characterized by transient spectral energy during the period. The spectrum of the zonal wind over Cachoeira Paulista-SP shows the almost simultaneous presence of spectral energy peaks in the range from $\sim 12$ to $\sim 48$ hours, between days 194 (July 12) and 200 (18 July), when the 24hour peak (diurnal tide) is the most intense. The wavelet spectrum of zonal wind over São João do Cariri-PB is characterized by the presence of energy in the range of 72-96 hours (3-4 days), between 158 and 178 days (June 6 and 26), and $\sim 48$ hours between days 178 and 201 (June 26 and July 19). The almost simultaneous presence of energy between $\sim 12$ and 48 hours can be seen around days 190 (July 8) and 204 (July 22). There is still one intense energy peak at $\sim 20$ hours around day 190 (July 8).

The meridional wind spectrum at Cachoeira Paulista-SP has energy associated with the diurnal tide during the time interval studied, with some momentaneous interruptions. Between days 168 (June 16) and 173 (June 23), a weak energy event is recorded for the period of $\sim 48$ hours (2-day wave). The energy associated with the $\sim 48$-hour period appears with greater intensity after day 197 (July 15) until day 203 (July 21). On this occasion, the energy spectrum spreads in the direction of the 16-hour periods. The meridional wind spectrum of Cariri-PB also features two energy peaks for the period of $\sim 48$ hours; the first, around day 174 (June 22) and the second around day 202 (July 20). Although less intense, energy associated with diurnal tide appears during the time interval considered. 


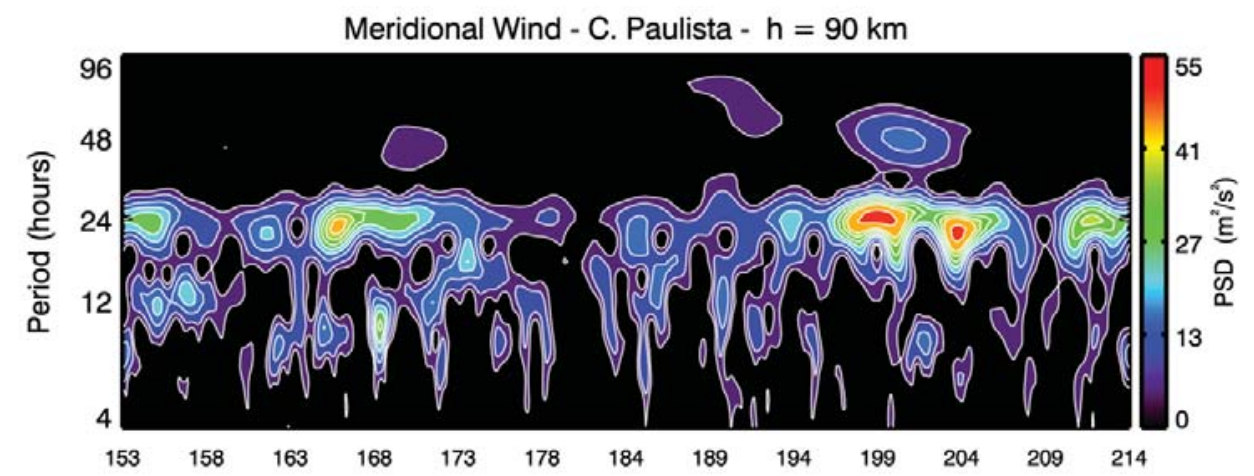

Zonal Wind - C. Paulista - $\mathrm{h}=90 \mathrm{~km}$

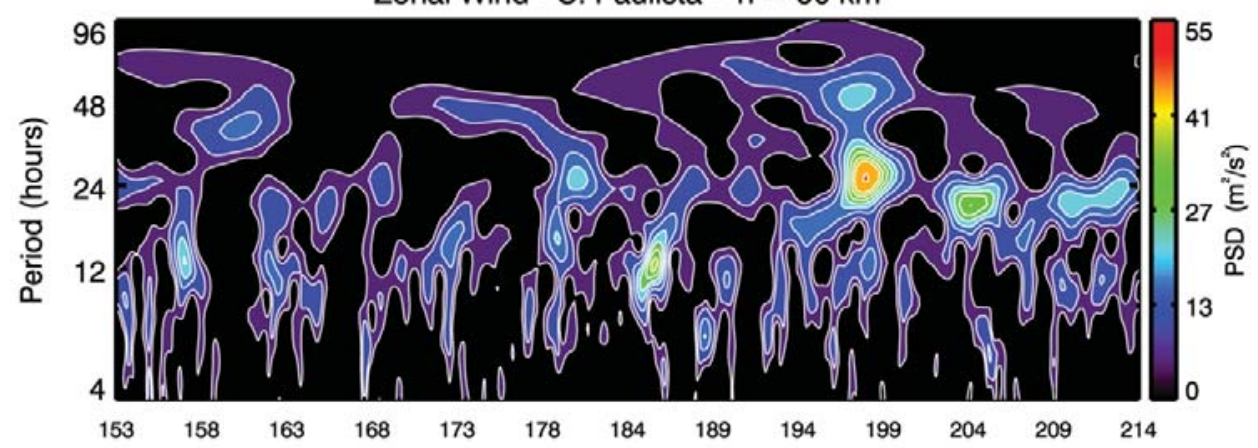

Meridional Wind - Cariri - $\mathrm{h}=90 \mathrm{~km}$
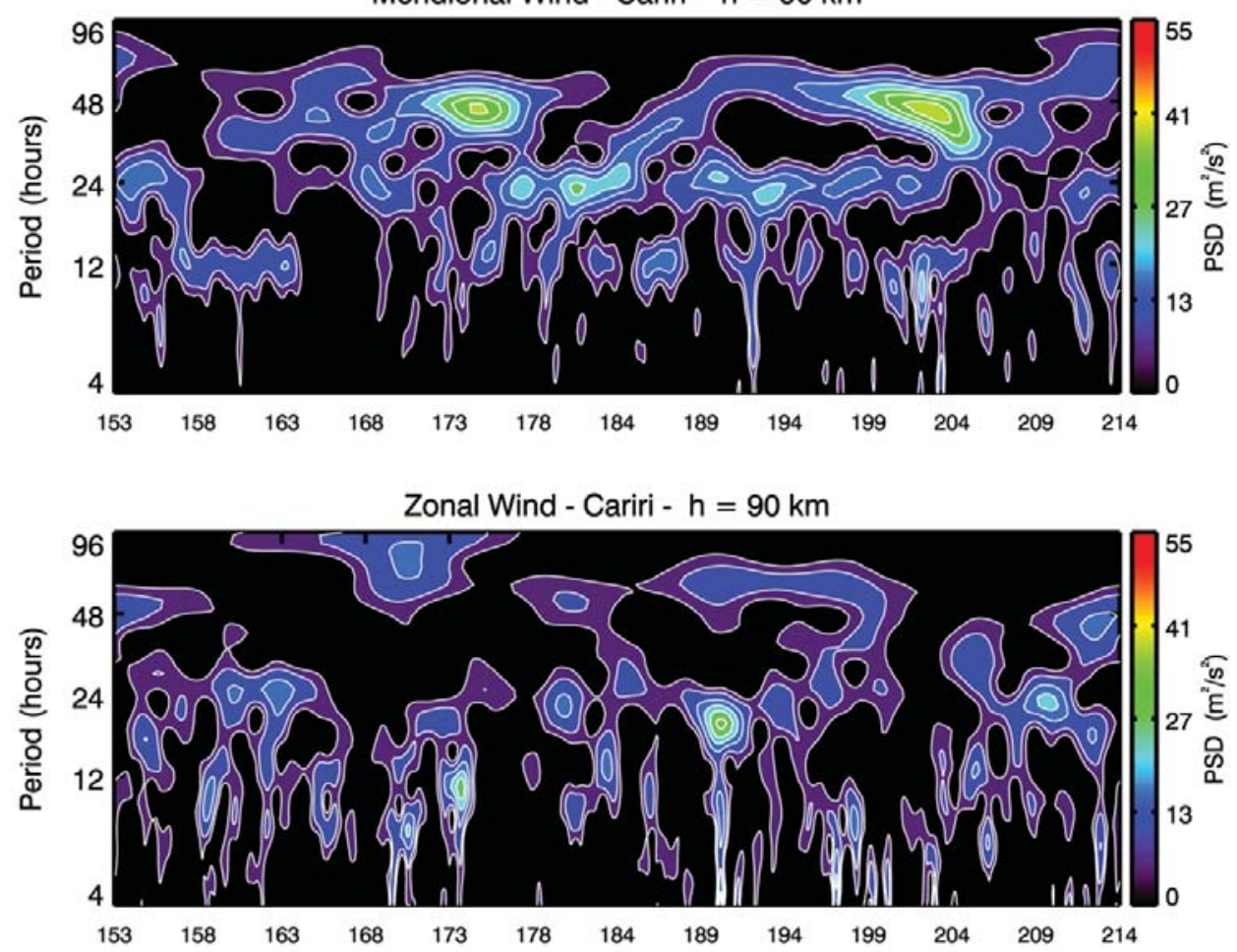

Figure 3 - Spectrum in the Morlet wavelet for the components of the zonal and meridional wind versus days of the year in the 90-km height layer, obtained over Cachoeira Paulista-SP and São João do Cariri-PB, for the period June-July 2008. 
The analysis of the Lomb-Scargle periodogram for the winds recorded in both sites, shows that between days 19 and 26 June, the periodogram of the zonal wind over Cachoeira Paulista, SP (Fig. 4a) displays spectral energy at $\sim 2, \sim 16, \sim 24$ and $\sim 45$ hours, peaking weakly at $\sim 80$ hours. For the meridional wind, the periodogram (Fig. 4b) shows energy peaks at $\sim 12,16$ and 24 hours, with a weak peak at 53 hours. For the same time interval, the periodogram for the meridional wind in São João do Cariri-PB (Fig. 4C) shows the presence of energy in $\sim 48$ hours besides weak peaks at 16 and 24 hours. The periodogram for zonal wind in São João do Cariri-PB (not shown here) has no significant spectral energy events for periods below 60 hours.
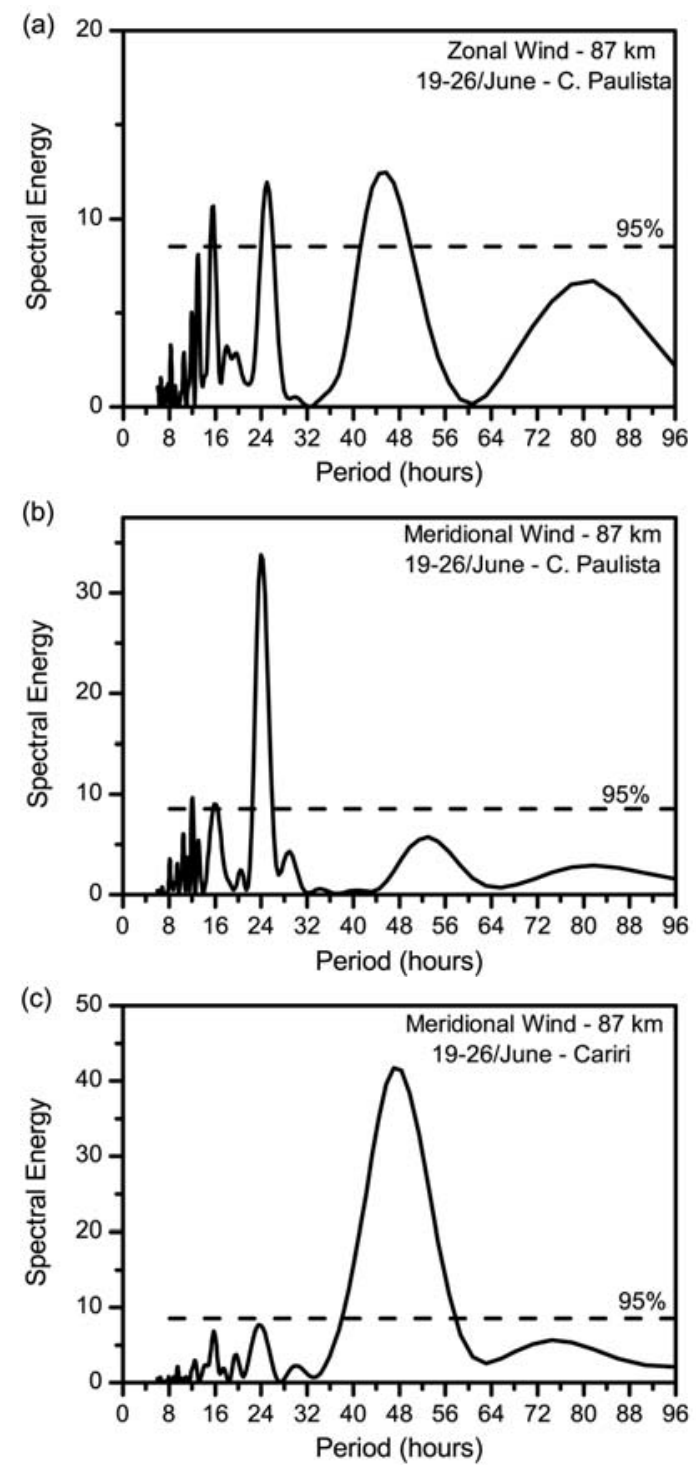

Figure 4 - Lomb-Scargle periodogram of the winds obtained between 21 and 28 June in Cachoeira Paulista-SP and São João do Cariri-PB for the 87-km layer. The dashed line indicates a confidence level of $95 \%$.
For the interval between July 21 and 28, the zonal wind periodogram over Cachoeira Paulista-SP (Fig. 5a) has spectral energy peaks at $\sim 16, \sim 18, \sim 21, \sim 37$ and $\sim 53$ hours while the meridional wind periodogram (Fig. 5b) displays energy at $\sim 16$, $\sim 18,20$ and 24 hours. The meridional wind periodogram for São João do Cariri-PB (Fig. 5 C) shows peaks of energy at $\sim 12,24$ and 48 hours, with a weak peak at $\sim 16$ hours. For the same time interval, the wind zonal events also did not show significant energy peaks.
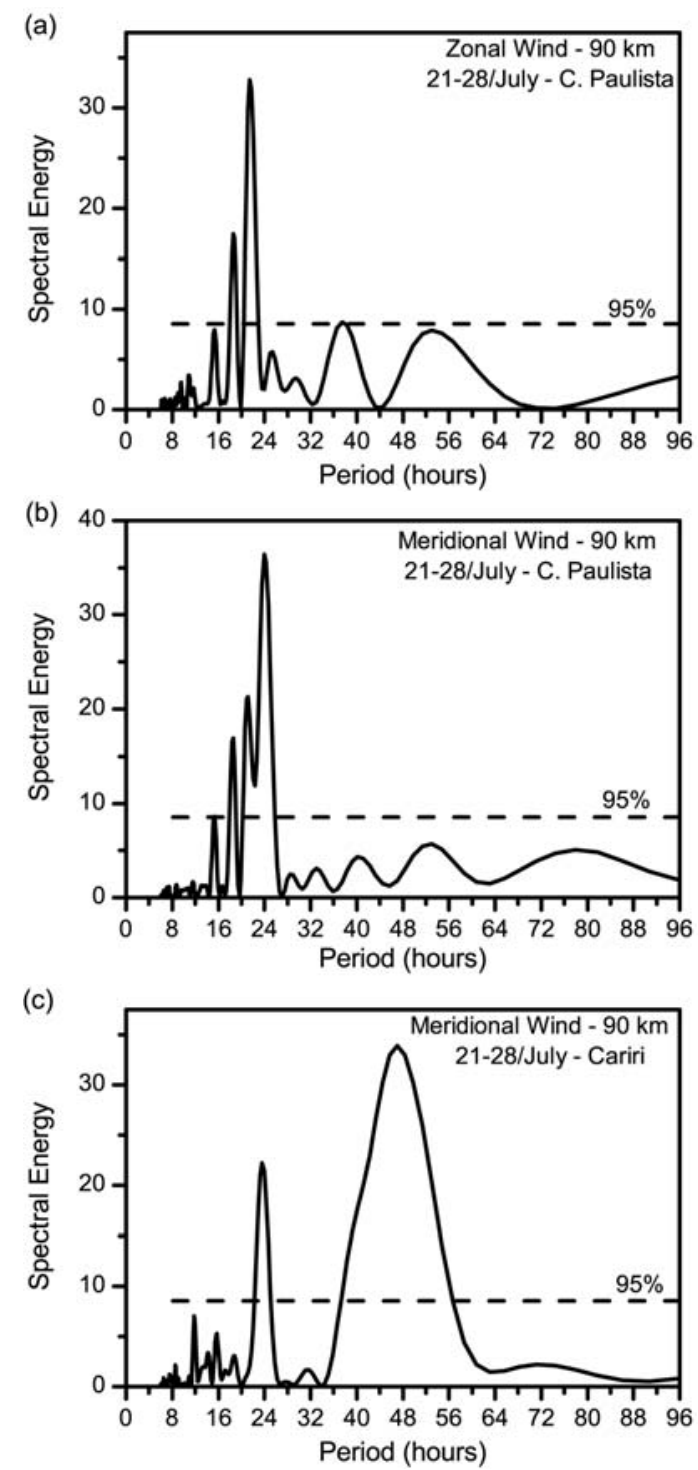

Figure $\mathbf{5}$ - Lomb-Scargle periodogram of the winds obtained between 21 and 28 July in Cachoeira Paulista-SP and São João do Cariri-PB for the 90-km layer. The dashed line indicates a confidence level of $95 \%$.

The plots of Figure 6 show maximum in the bi-frequencies (0.5 and 1.0) corresponding to sum triplet $(0.5,1.0,1.5)$. These 
results support the hypothesis that the coupling between the diurnal tide ( 1 cycle/day) and 2-day wave ( 0.5 cycles/day) generated the secondary wave of 16 hours ( 1.5 cycles/day) observed in the zonal and meridional wind measurements at Cachoeira Paulista-SP and meridional wind at São João do Cariri-PB, between June 16 and 29, 2008.
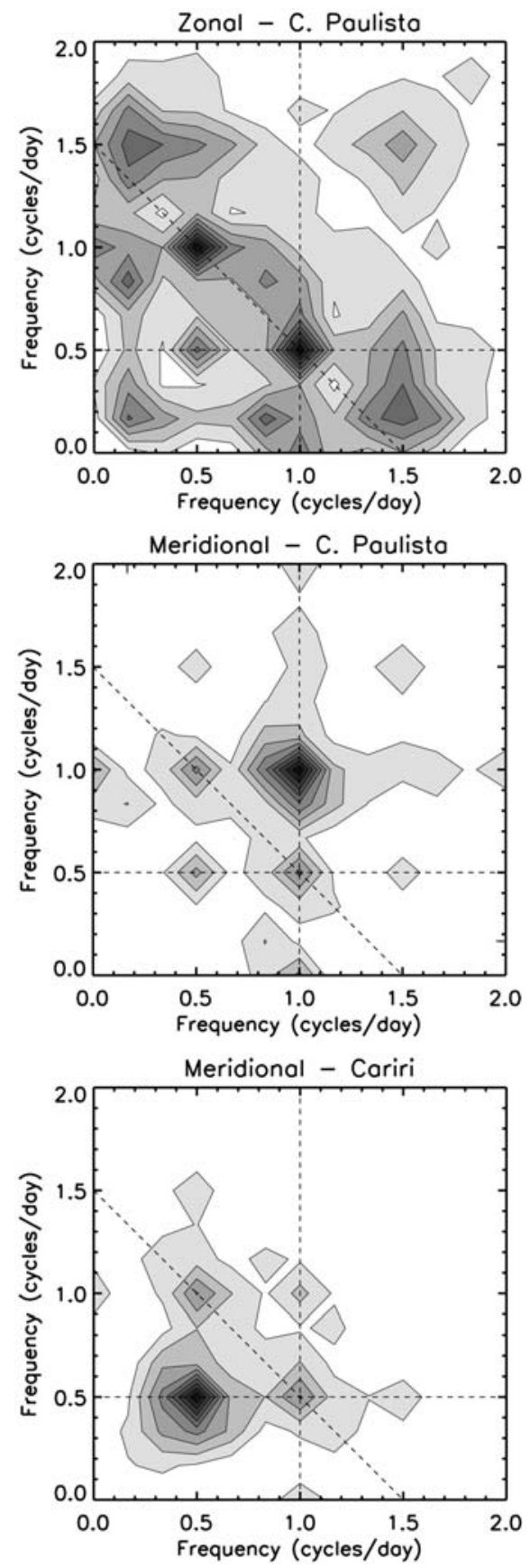

Figure $\mathbf{6}$ - Bispectra corresponding to the zonal and meridional wind data obtained in Cachoeira Paulista-SP and meridional wind in São João do Cariri-PB for the 87-km layer, between June 16 and 29, 2008. Regions in gray indicate the occurrence of nonlinear interaction.
Figure 7 shows the results of the bispectral analysis of the wind data recorded for $\mathrm{C}$. Paulista-SP and S.J. Cariri-PB between July 15 and 28. The zonal wind plot of $C$. Paulista displays energy in the bi-frequencies close to (0.5 and $\sim 1.2$ ) cycles/day, the sum results in a secondary wave with a frequency of $\sim 1.7 \mathrm{cy}-$ cles/day ( $\sim 14$ hours) while the difference results in a frequency of $\sim 0.7$ cycle/day ( $\sim 34$ hours). Energy burst during the periods $\sim 15$ hours and $\sim 37$ hours are observed in the periodogram of Figure 5a. The bispectrum meridional wind at C. PaulistaSP clearly shows energy corresponding to the triplet $(0.5,1.0$, 1.5) cycles/day, i.e., corresponding to the interaction between the diurnal tide and 2-day wave resulting in secondary wave of 16 hours. On the other hand, the wind data obtained for S.J. Cariri-PB during the same time interval did not reveal the presence of coupling between diurnal tide and 2-day waves.

Palo et al. (1999) used a global circulation model for the month of January and showed that the nonlinear interaction between the quasi-two-day wave and the diurnal and semidiurnal tidal modes can produce a series of secondary and tertiary waves. According to the simulation, the secondary waves generated by the nonlinear interaction between $\sim 2$-day wave and migrant diurnal tide are the wave of 16 hours with zonal wave number $s=4$ that travels east-west, and the $\sim 2$-day wave with zonal wave number $s=2$, which propagates from west to east.

In general, studies about the interaction between the $\sim 2$-day wave and tidal modes are concentrated during the months when the $\sim 2$-day wave is more intense (January-February). However, the results revealed, through a set of analysis for the data obtained at C. Paulista-SP and S.J. do Cariri-PB during June and July 2008, support the hypothesis that occurrences of 16-hour waves observed in the wind measurements, resulted from the nonlinear interaction between the $\sim 2$-day waves and the diurnal tide. Pancheva (2006) used wind measurements obtained by meteor radar Ascension Island $\left(7.9^{\circ} \mathrm{S}, 14.4^{\circ} \mathrm{W}\right)$ to investigate variations of the tidal wave in the presence of $\sim 2$-day wave during January to February 2003. The results indicated that the waves of 9.6 hours and 16 hours were generated by nonlinear interaction between $\sim 2$-day wave and semidiurnal and diurnal tide modes, respectively.

In both cases examined, the presence of spectral energy in the period of $\sim 16$ hours may be interpreted as arising from the interaction between the tide of 24 hours and the wave $\sim 48$ hours (about two days). According to theoretical studies, the nonlinear interaction between two primary waves with periods of 24 and 48 hours yields a family of secondary waves, among which, two with frequencies that result from the sum and the 
difference of the primary waves frequencies. That is, two secondary waves with periods near 16 and 48 hours are generate in this case.
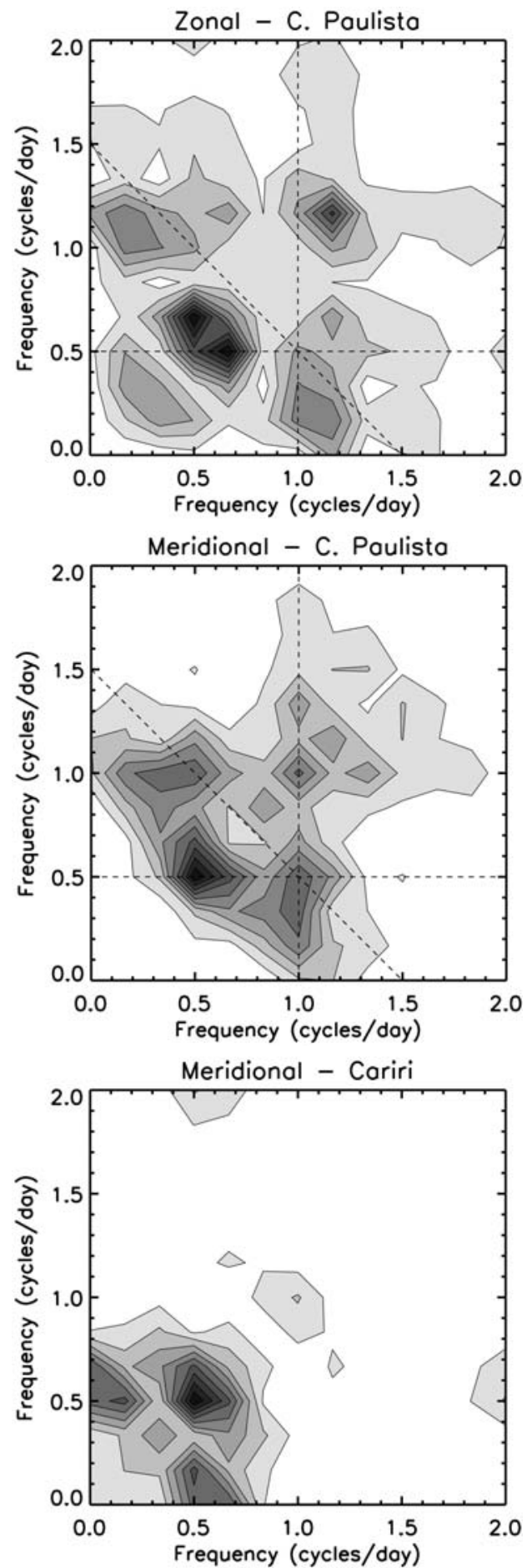

Figure 7 - Bispectra corresponding to the zonal and meridional wind data obtained in C. Paulista-SP and meridional wind in São João do Cariri-PB for the 90-km layer, between July 15 and 28, 2008. Regions in gray indicate the occurrence of nonlinear interaction.

\section{CONCLUSIONS}

The analysis of the MLT winds, obtained by meteor radars in São João do Cariri-PB and Cachoeira Paulista-SP during June and July 2008, displayed changes consistent with typical nonlinear interaction between modes of atmospheric waves.

The results of wavelet spectra, as well as the localized LombScargle periodograms referring to the time series of the zonal and meridional components of the wind at the two sites showed the presence of near simultaneous spectral energy peaks in the periods of $\sim 16, \sim 24$ and $\sim 48$ hours compatible with the occurrence of interaction between the 48-hour (2-day waves) and 24-hour (diurnal tide) waves, with consequent generation of 16-hour wave.

Additionally, the bispectral results of the winds confirmed the occurrence of non-linear coupling between the primary waves (two days and diurnal tide) with the generation of secondary wave (16 hours).

Although the study considered wind measurements obtained during the months from June to July, when the $\sim 2$-day wave is less intense, the results agree with those obtained in studies for the months from January to February in which, in general, $\sim 2$-day wave is more intense.

\section{ACKNOWLEDGMENTS}

The authors thank the Instituto Nacional de Pesquisas Espaciais - INPE and Observatório de Luminescência Atmosférica da Paraíba - OLAP, for their collaboration and the availability of the meteor radar data. The meteor radar at Cachoeira Paulista-SP was purchased with funds from CNPq/PRONEX and the one from São João do Cariri-PB with funds from the FAPESP thematic project. This work was partially supported by the Conselho Nacional de Desenvolvimento Científico e Tecnológico - CNPq, and by the Universidade Estadual da Paraíba - UEPB through the PROPESQ.

\section{REFERENCES}

BEER T. 1975. Atmospheric waves. Adam Hilder, London, 300 pp.

CHAPMAN S \& LINDZEN RS. 1970. Atmospheric tides. Dordrecht: D. Reidel Publishing Company, 200 pp.

FORBES JM. 1982. Atmospheric tides. 1. Model description and results for the solar diurnal components. J. Geophys. Res., 87: 5222-5240.

FORBES JM \& VIAL F. 1989. Monthly simulation of the solar semidiurnal tide in the mesosphere and lower thermosphere. J. Atmos. Terr. Phys., 51: 649-661. 
GURUBARAN S, RAJARAM R, NAKAMURA T \& TSUDA T. 2005. Interannual variability of diurnal tide in the tropical mesopause region: A signature of the El Nino-Southern Oscillation (ENSO). Geophys. Res. Lett., 32: L1380.

HAGAN ME, BURRAGE MD, FORBES JM, HACKNEY J, RANDEL WJ \& ZHANG X. 1999. QB0 effects on the diurnal tide in the upper atmosphere. Earth Planets Space, 51: 571-569.

HAGAN ME, ROBLE RG \& HACKNEY J. 2001. Migrating thermospheric tides. J. Geophys. Res., 106: 12739-12752.

HORNES JH \& BALIUNAS SL. 1986. A Prescription for period analysis of unevenly sampled times series. The Astrophysical Journal, 302: 757-763.

KUMAR P \& FOUFOULA-GEORGIOUE. 1997. Wavelet analysis for geophysical applications. Reviews Geophys., 35(4): 385-412.

LIEBERMAN RS, RIGGIN DM, ORTLAND DA, NESBITT SW \& VINCENT RA. 2007. Variability of mesospheric diurnal tides and tropospheric diurnal heating during 1997-1998. J. Geophys. Res., 112: D20110.

LIMA LM, BATISTA PP, TAKAHASHI H \& CLEMESHA BR. 2004. Quasitwo-day wave observed by meteor radar at $22.7^{\circ} \mathrm{S}$. J. Atmos. Solar-Terr. Phys., 66: 529-537.

LIMA LM, BATISTA PP, CLEMESHA BR \& TAKAHASHI H. 2005. The 6.5-day Oscillations Observed in Meteor Winds over Cachoeira Paulista (22.70S). Adv. Space Res., 36: 2212-2217.

McLANDRESS C. 1997. Seasonal variability of the diurnal tide: Results from the Canadian middle atmosphere general circulation model. J. Geophys. Res., 102: 29747-29764.

McLANDRESS C. 2002. Interannual variations of the diurnal tide in the mesosphere induced by a zonal-mean wind oscillation in the tropics, Geophys. Res. Lett., 29: 1305-1308.

NIKIAS CL \& PETROPULU AP. 1993. Higher-order spectra analysis: a nonlinear signal processing framework. Prentice-Hall, New Jersey, $537 \mathrm{pp}$.

PALO SE, ROBLE RG \& HAGAN ME. 1999. Simulation of the quasi-twoday wave using the TIME-GCM: Dynamical effects in the middle atmosphere. Earth Planets Space, 51: 629-647.

PANCHEVAD. 2000. Evidence for nonlinear coupling of planetary waves and tides in the lower thermosphere over Bulgaria. J. Atmos. Solar-Terr. Phys., 62: 115-132.
PANCHEVA DV. 2006. Quasi-2-day wave and tidal variability observed over Ascension Island during January/February 2003. J. Atmos. SolarTerr. Phys., 68: 390-407.

PLUMB RA. 1983. Baroclinic instability of the summer mesosphere: a mechanism for the quasi-two-day wave? J. Atmos. Sci., 40: 262-270.

SALBY ML. 1981. The 2-day wave in the middle atmosphere - observations and theory. Journal of Geophysical Research, 86(C10): 96549660.

SALBY ML \& CALLAGHAN PF. 2001. Seasonal amplification of the 2day wave: relationship between normal mode and instability. J. Atmos. Sci., 58: 1858-1869.

SCARGLE JD. 1982. Studies in astronomical time series analysis. II Statistical aspects of spectral analysis of unevenly spaced data. Astrophys. J., Part 1, 263: 835-853.

SPIZZICHINO A. 1969a. Étude des interactions entre les différentes composants du vent dans la haute atmosphère (Deuxième partie: Quelques données sur la propagation des ondes atmosphériques). Ann. Géophys., 25: 755-771.

SPIZZICHINO A. 1969b. Étude des interactions entre les différentes composants du vent dans la haute atmosphère (Troisième partie: Théorie des interactions non linéaires entre les ondes atmosphériques). Ann. Géophys., 25: 773-783.

TEITELBAUM H \& VIAL F. 1991. On tidal variability induced by nonlinear interaction with planetary waves. J. Geophys. Res., 96: 1416914178.

TEITELBAUM H, VIAL F, MANSON AH, GIRALDEZ R \& MASSEBOEUF M. 1989. Non-linear interaction between the diurnal and semidiurnal tides: terdiurnal and diurnal secondary waves. J. Atmos. Terr. Phys., 51: $627-634$.

TORRENCE C \& COMPO GP. 1998. A practical guide to wavelet analysis. Bull. Am. Meteor. Soc., 79: 61-78.

VINCENT RA, KOVALAM S, FRITTS DC \& ISLER JR. 1998. Long-term MF radar observations of solar tides in the low-latitude mesosphere: Interannual variability and comparisons with the GSWM. J. Geophys. Res., 103: 8667-8684.

WALTERSCHEID RL \& VINCENT RA. 1996. Tidal generation of the phase-locked 2-day wave in the southern hemisphere summer by wavewave interactions. J. Geophys. Res., 101: 26567-26576. 


\section{NOTES ABOUT THE AUTHORS}

Edvaldo de Oliveira Alves graduated in electrical engineering (UFPB - 1992), has a degree in Physics (UEPB - 1992), as well as a Master degree in Physics (UFRN - 2007) and Meteorology (UFCG - 2007) and Ph.D. in Meteorology (UFCG - 2012). Currently, works as a professor at the Universidade Estadual da Paraíba - UEPB, developing studies on the dynamics of middle and upper atmosphere fields.

Lourivaldo Mota Lima has a degree in Physics from the Universidade Regional do Nordeste (URNe - 1985). Holds a Masters in Meteorology from the Universidade Federal da Paraíba (UFPB - 1995), and Ph.D. in Geophysics from the Instituto Nacional de Pesquisas Espaciais (INPE - 2004). Currently, is a professor at the Universidade Estadual da Paraíba - UEPB, working in the area of dynamics of middle and upper atmosphere.

Amauri Fragoso de Medeiros has a Physics degree from the URNe (1984). Holds a Masters in Science Education from the Universidade de São Paulo (USP - 1995), and Ph.D. in Space Geophysics from INPE (2001). Currently, works as a professor at the Universidade Federal de Campina Grande - UFCG, in the area of Aeronomy.

Ricardo Arlen Buriti has a Physics degree from UFPB (1984), Masters in Physico-Chemistry from USP (1987), and Ph.D. in Space Geophysics from INPE (1997). Currently, works as a Professor at UFCG, in the area of Aeronomy.

Paulo Prado Batista graduated in Physics from the Universidade Federal de Goiás (1972). Joined INPE in 1973 and obtained his Masters in Space Science in 1977 and Ph.D. in 1983. Currently, conducts studies on the dynamics of middle and upper atmosphere.

Barclay Robert Clemesha has a BS degree in Physics from the University of London (1957), and Ph.D. in Physics from the University of the West Indies (1968). Works as a researcher at INPE since late 1968, developing dynamics and chemistry studies of high mesosphere and lower thermosphere. 